\title{
Heat transfer characteristics for inclined twin-jet impingement
}

\author{
M. Kito ${ }^{1}$, T. Matsumoto ${ }^{1}$, T. Shakouchi ${ }^{2}$, K. Tsujimoto ${ }^{2}$ \\ $\& \mathrm{~T}$. Ando ${ }^{2}$ \\ ${ }^{I}$ Department of Mechanical Engineering, \\ Suzuka National College of Technology, Japan \\ ${ }^{2}$ Graduate School of Engineering, Mie University, Japan
}

\begin{abstract}
Determining the local heat transfer coefficient on a target surface is essential for many engineering applications. Numerous studies of the heat transfer and flow characteristics for jet impingement on surfaces have been published. However, few studies have been reported about the heat transfer characteristics of inclined, as opposed to perpendicular or normal, impinging jets. Further, few studies have been reported on twin impinging jets. In this study, local Nusselt number $(\mathrm{Nu})$ distributions on the target plate were obtained for $\mathrm{Re}=5000$ (based on the hydraulic diameter of the slot nozzle, $\left.\mathrm{D}_{\mathrm{h}}\right)$, the nozzle-to-plate spacing $\left(\mathrm{H} / \mathrm{D}_{\mathrm{h}}=2\right)$, the nozzle-to-nozzle spacing $\left(L / \mathrm{D}_{\mathrm{h}}=3,5\right.$ and 7$)$ and various twin-jet angles $\left(\theta=0,15,30\right.$ and $\left.45^{\circ}\right)$. For $\theta=0^{\circ}$, two primary stagnation points having maximum $\mathrm{Nu}$ numbers appeared at the geometrical impingement points of the each jet. A secondary stagnation point occurs in the mid-point between jets at $L / \mathrm{D}_{\mathrm{h}}=5$ and 7 . However, the secondary stagnation disappeared at lower nozzle-to-nozzle spacing $\left(L / D_{h}=3\right)$.The primary $\mathrm{Nu}$ peak shifts away from the geometrical impingement point and the value of the primary $\mathrm{Nu}$ peak decreased as the inclination angle increased. When two jets were inclined in the same direction, the decrease in the first peak was smaller than that in the second peak with the increasing angle of the jets. On the other hand, the values of both peaks' Nu were almost the same when two jets were inclined to face each other.

Keywords: heat transfer, inclined twin jets, jet cooling, turbulent flow, slot jet nozzle.
\end{abstract}




\section{Introduction}

Impinging jets are used in a wide variety of applications to dry off wet surfaces or especially, to cool heated objects because of their high heat and mass-transfer characteristics in the stagnation region. Therefore, many researchers have investigated the effects of nozzle configuration including non-circular nozzles to improve the heat transfer rate on the target plate and the mechanism of the turbulent heat transfer [1-3]. Viskanta [4] provided detailed reviews of impingement heat transfer. Since the understanding of free jets is essential to reveal the mechanism of impinging jets and improve technical methods, the effects of nozzle configurations, jet velocity, and ambient conditions have been well addressed. Single impinging jets have been especially well studied, and it is well known that the heat transfer characteristics improve when jets impinge at the potential core length because of their high turbulence intensities and adequate velocity. However, while high heat transfer can be obtained at the stagnation region, the heat transfer rapidly decreases in the downstream.

Some researchers have reported the improvement of cooling efficiency and the heat transfer in the downstream using multi-impinging jets and turbulence promoters. Still, the majority of investigators have dealt with single impinging jets which impinge on a plate perpendicularly, not inclined multi-impinging jets. Regarding inclined impinging jets, Beitelmal et al. [5] studied the effects of inclination for a single rectangular jet, and Abdel-Fattah [6] demonstrated the flow structures for twin jets which are obliquely arranged. However, a problem seems to lie in the fact that the high heat transfer coefficient of a jet decays rapidly with the increase of distance downstream of the stagnation point. In this paper, we present the heat transfer characteristics of inclined-jet and inclined twin-jet impingement.

\section{Experimental procedure}

Figure 1 shows our experimental apparatus for measuring the temperature of the target plate. The target plate was made of Bakelite and was $20 \mathrm{~mm}$ thick. Thin $40-\mu \mathrm{m}$ stainless steel foil applied on the plate was directly heated with uniform heat flux adjusted using a variable transformer. The amount of Joule heating was calculated considering the heat transfer rate to the plate and the thermal radiation from the foil surface. Twenty-five thermocouples (C-A) were embedded just behind the foil to measure the temperature distributions on the plate simultaneously using a data logger with 0.1-degree accuracy.

The normalized nozzle-plate distance was kept at $H / \mathrm{D}_{\mathrm{h}}=2$ where $\mathrm{D}_{\mathrm{h}}$ is the hydrical diameter, and the Reynolds number $\mathrm{Re}=5000$ was a constant, while the nozzle angle was changed from 0 to 60 degrees. We conducted three experiments; a single inclined impinging jet, twin impinging jets inclined in the same direction, and twin impinging jets inclined to face each other (see Figure 2). The effects of jet spacing $L$ on the heat transfer were also investigated. As shown in Figure 2(a) the direction toward which the nozzle inclined is defined as the "uphill side" and the other direction is defined as the "downhill 
side". The coordinate system takes $x$ starting from the center of the plate to the downhill side. The nozzle used in this experiment had a rectangular exit area $5 \mathrm{~mm} \times 50 \mathrm{~mm}$, giving it an aspect ratio of 10 .

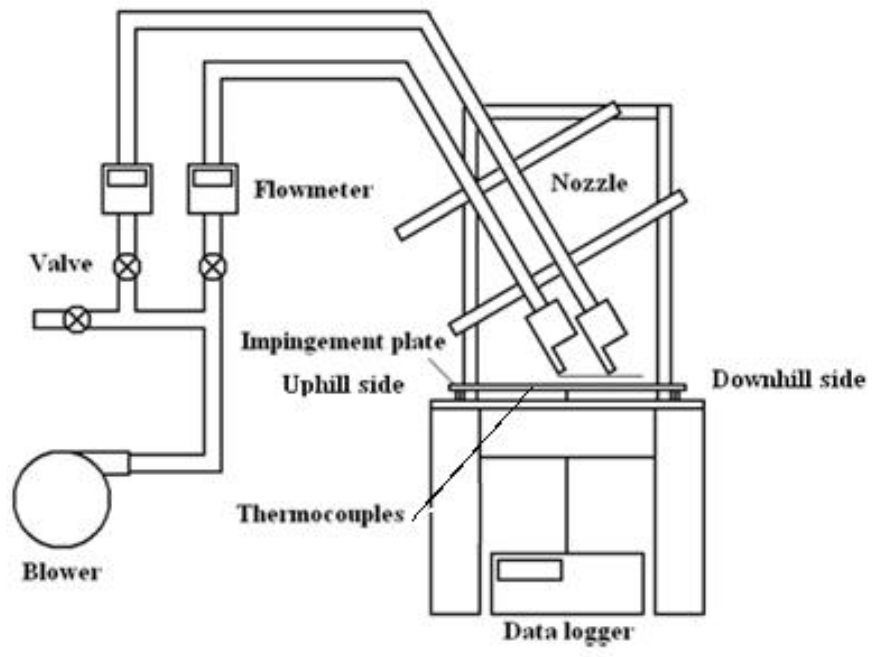

Figure 1: $\quad$ Experimental apparatus.

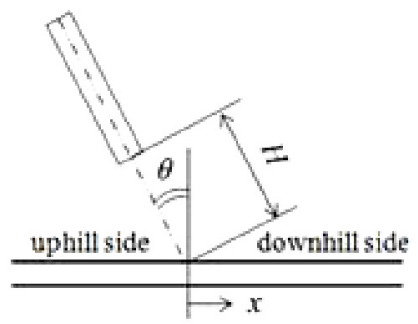

(a)

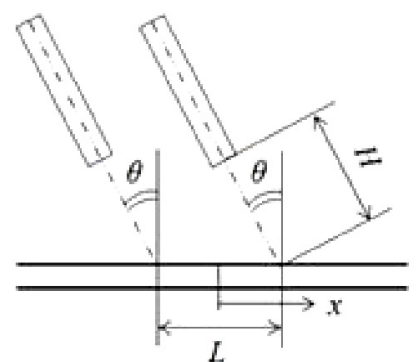

(b)

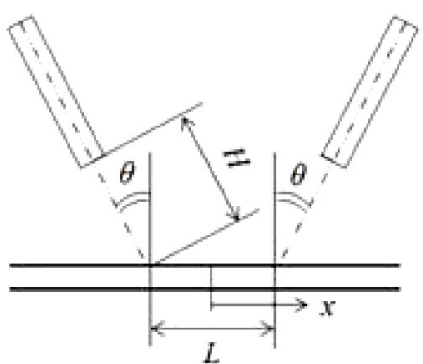

(c)

Figure 2: Coordinate systems for single and inclined twin impinging jets. 
In order to investigate the nozzle properties, the free jet velocity was measured without the impingement plate. Figure 3 shows the mean velocity distribution at the nozzle exit to understand the velocity uniformity of the nozzle. The profile was found to be nearly a top-hat, at least at the center. The normalized centerline velocities $u / \mathrm{U}_{\max }\left(\mathrm{U}_{\max }\right.$ is the initial velocity at the nozzle exit) of the nozzle at $\mathrm{Re}=5000$ are shown in Figure 4 . The centerline velocity remained almost constant from the nozzle exit up to $H / \mathrm{D}_{\mathrm{h}} 2.0$ where $\mathrm{D}_{\mathrm{h}}$ is the hydraulic diameter. Thus, the potential core of this nozzle was found to be $H / \mathrm{D}_{\mathrm{h}}$ $\approx 2.0$. Thereafter, the velocity decayed with $u / \mathrm{U}_{\max } \propto\left(H / \mathrm{D}_{\mathrm{h}}\right)^{-0.5}$ in the fully developed region, which is the distinctive equation in the fully developed region for a rectangular nozzle.

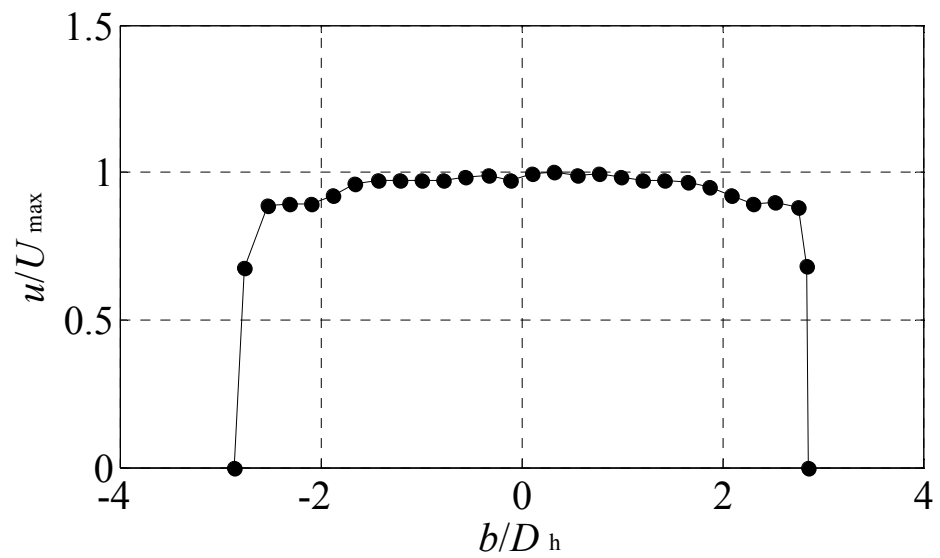

Figure 3: The mean velocity at the nozzle exit.

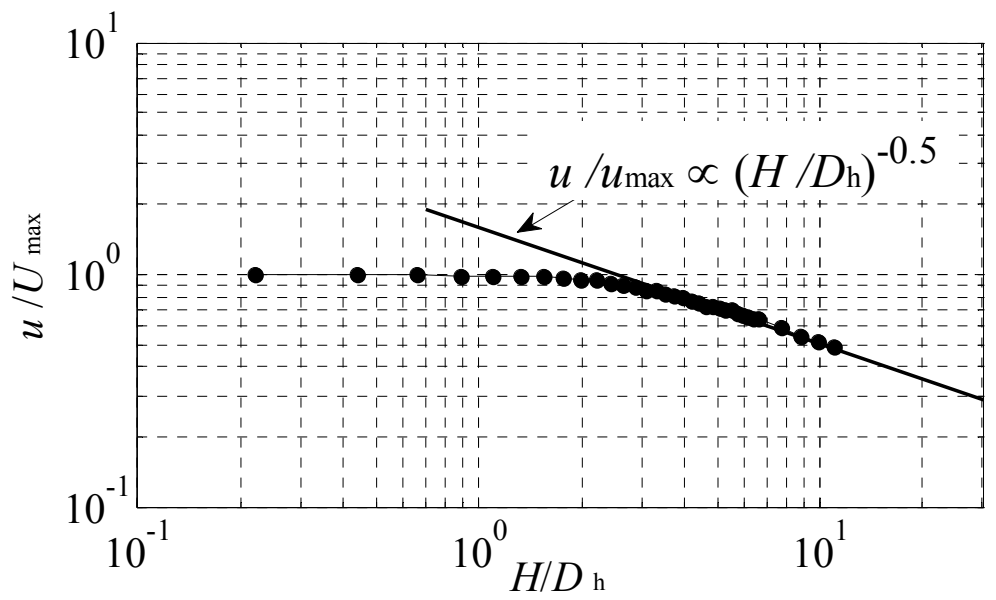

Figure 4: The centreline mean velocity. 
Before investigating the effects of jet inclination on the heat transfer characteristics, a validity check was conducted. Figure 4 demonstrates the heat transfer at $\mathrm{Re}_{\mathrm{B}}=10000, H / \mathrm{B}=10$. The stagnation $\mathrm{Nu}$ when a rectangular nozzle jet impinges was evaluated as follows [7].

$$
N u_{B}=1.42 \cdot \operatorname{Pr}^{0.43} \cdot \operatorname{Re}_{B}^{0.58} \cdot(H / B)^{-0.02} \quad\left(10^{4}<\operatorname{Re}_{\mathrm{B}}<2 \times 10^{5}\right),
$$

where $\mathrm{Re}_{\mathrm{B}}$ is the Reynolds number based on the nozzle width $\mathrm{B}$. The nozzle used in this experiment had the nozzle exit width $B=5 \mathrm{~mm}$ and the spacing between nozzle and the target plate was $50 \mathrm{~mm}$. The stagnation $\mathrm{Nu}$ was 65.3 calculated from the temperature distribution along the target plate and $\mathrm{Nu}_{\mathrm{B}}=61.3$ was obtained from eq. (1). Good agreement of about $6.7 \%$ was achieved for the impingement cooling characteristics. The uncertainty in the Nusselt number was less than $4.8 \%$ based on the standard uncertainty analysis.

An acrylic flat plate was used to measure the pressure distribution on the plate. At each $x$-location for the streamwise pressure measurements, static pressure holes of $0.1 \mathrm{~mm}$ were carefully installed on the plate. The plate surface where pressure holes were drilled was free from remaining frilling defects of the holes $5 \mathrm{~mm}$ interval $\pm 0.1 \mathrm{~mm}$.

The pressure coefficient was defined as follows.

$$
C p=\frac{2 \cdot \Delta p}{\rho u^{2}}
$$

where $\rho$ is the density of air, $u$ is the jet velocity and $\Delta p$ is the pressure difference between the pressure on the plate and the atmospheric pressure.

\section{Results and discussion}

\subsection{Single inclined impinging jet}

Maximum heat transfer occurs at the stagnation point and the local $\mathrm{Nu}$ decreases gradually in the downstream when a single jet impinges on the plate in a direction normal to the plane. Figure 5 demonstrates the location of the maximum $\mathrm{Nu}$ of single impinging jets when the nozzle angle $\theta$ is changed from 0 to 60 degrees. The maximum Nu shifts to the uphill side and its value decreases as the angle increases. It is worth noting that the shift value increases and reaches its maximum at 45 degrees. At $\theta>45^{\circ}$, the maximum $\mathrm{Nu}$ shifts back to the downhill side.

Figure 6 shows the pressure distributions along the plate with $\theta$ from 0 to 60 degrees. The maximum pressure shifts to the uphill side in the same manner as the maximum $\mathrm{Nu}$ in Figure 5. Therefore, the pressure distribution is related to 


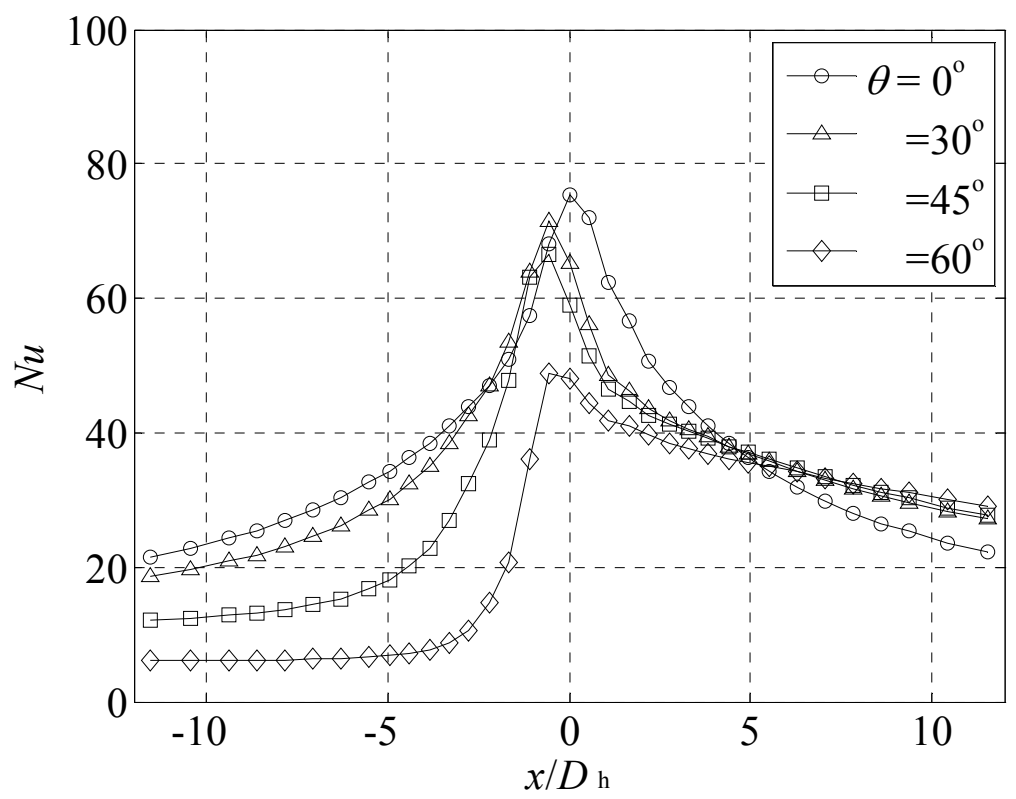

Figure 5: $\quad$ Local $\mathrm{Nu}$ for single inclined impinging jet.

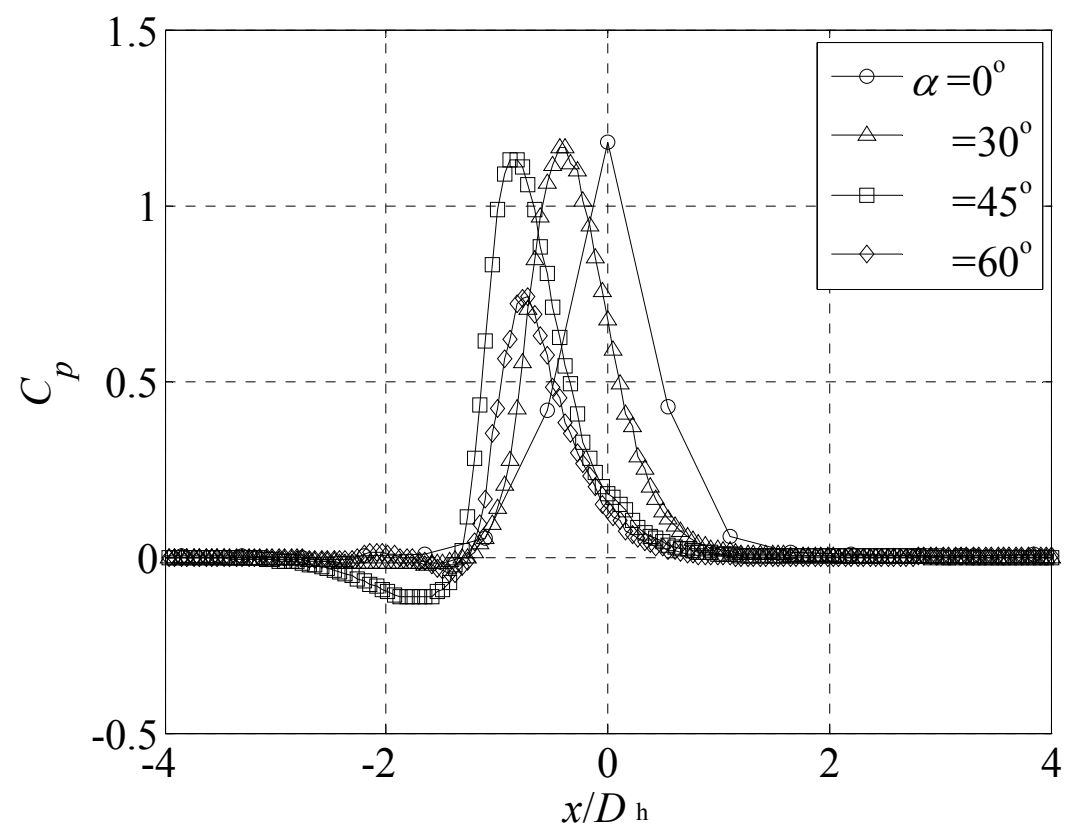

Figure 6: $\quad$ Pressure distribution. 
the heat transfer on the plate. The shift value of the pressure peak was about 0.4 $D_{h}$ to the uphill side from the stagnation point at 30 degrees and about $0.8 D_{h}$ at 45 degrees. The shift value gradually increased with increasing $\theta$. The maximum shift value appeared at 45 degrees because the peak shifted about $0.7 D_{h}$ to the stagnation point at 60 degrees. The location of each maximum pressure reading coincided with that of each maximum $\mathrm{Nu}$.

Figure 7 shows the variation of average $\mathrm{Nu}$ over the plate $\left(-12<x / \mathrm{D}_{\mathrm{h}}<12\right)$ and in the downstream $\left(-12<x / \mathrm{D}_{\mathrm{h}}<-6 ; 6<x / \mathrm{Dh}<12\right)$. The increasing rate of the average $\mathrm{Nu}$ compared with the normal impinging jet is also presented in Figure 8 . The average $\mathrm{Nu}$ over the plate decreases as $\theta$ increases; however, the maximum values of $\mathrm{Nu}$ at $\theta<30^{\circ}$ are as high as that of the normal jet. The average $\mathrm{Nu}$ over the plate rapidly decreases at $\theta>30^{\circ}$. This explains that the small inclination of a jet $\theta<30^{\circ}$ hardly affects the heat transfer characteristics over the plate, while inclinations of $\theta>30^{\circ}$ cause significant decrease in the heat transfer. The average $\mathrm{Nu}$ in the uphill side decreases as $\theta$ increases. Especially, at $\theta>30^{\circ}$ the average $\mathrm{Nu}$ in the uphill side decreases significantly. On the contrary, the average $\mathrm{Nu}$ in the downhill side increases as $\theta$ increases. The average $\mathrm{Nu}$ increased a maximum of $19 \%$ in the downhill side compared with the normal jet. Since a flat average $\mathrm{Nu}$ can be obtained in the downhill side, an inclined impinging jet can uniformly cool a heated plate in the downstream.

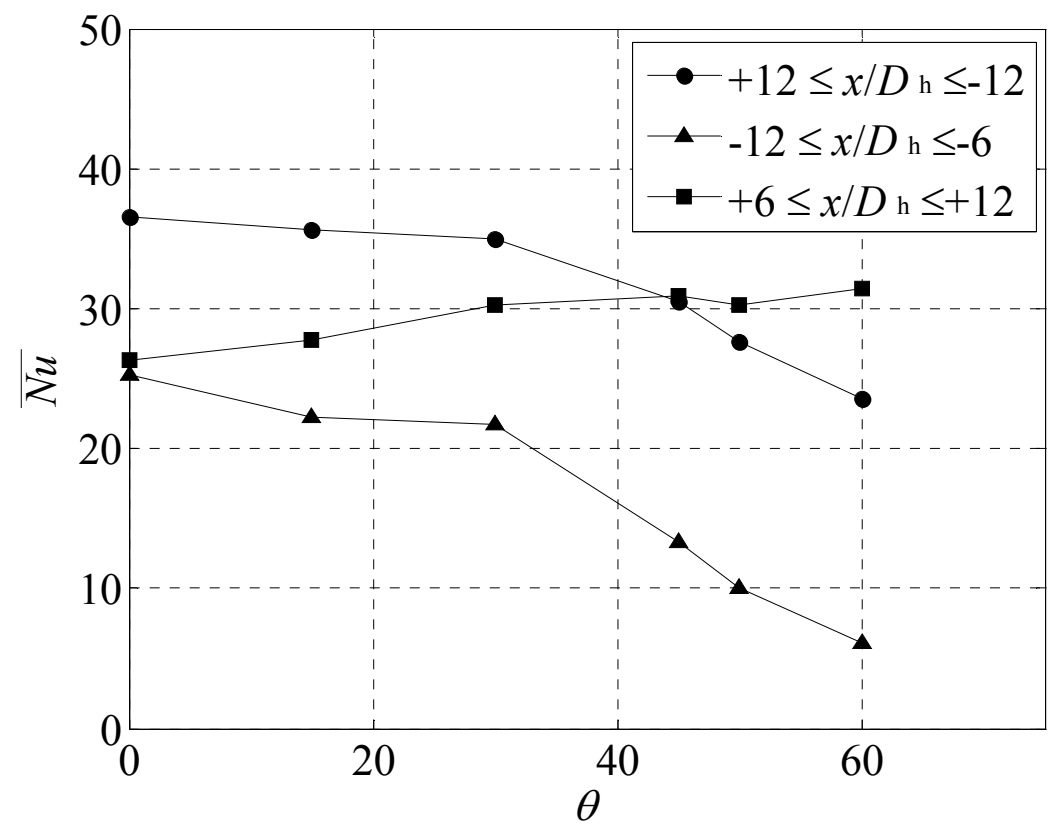

Figure 7: Variation of average $\mathrm{Nu}$. 


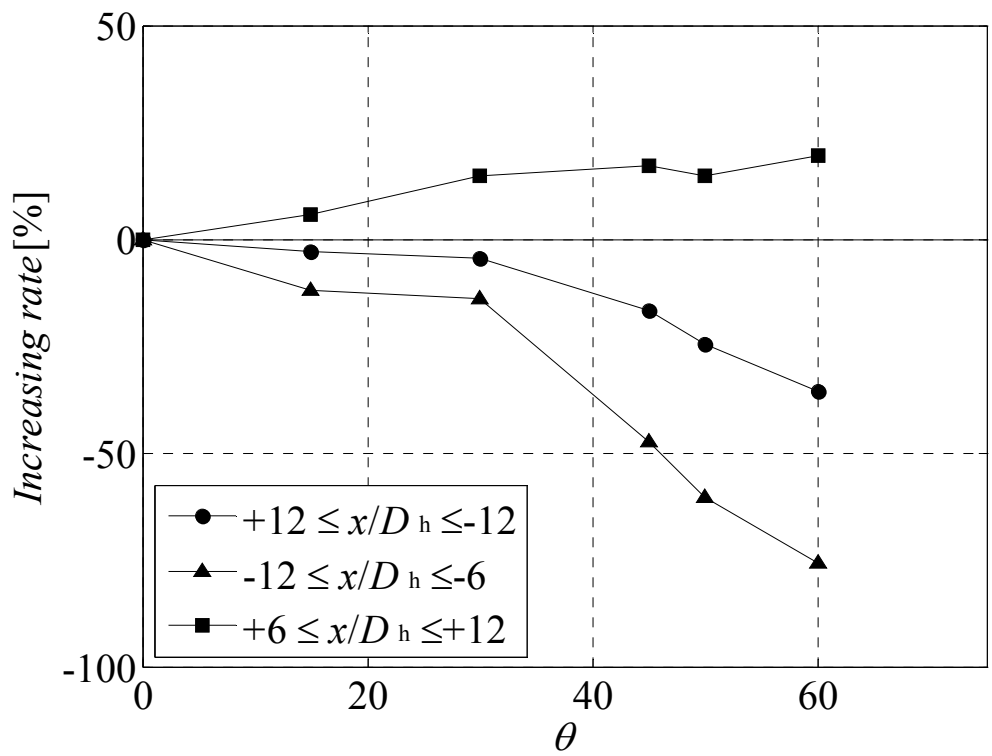

Figure 8: Increasing rate of the average $\mathrm{Nu}$ compared with normal impinging jet.

\subsection{Twin impinging jets}

Figure 9 shows the local $\mathrm{Nu}$ when the jet spacing was changed from $L / \mathrm{D}_{\mathrm{h}}=3$ to 7. In the case of $\theta=0^{\circ}$, two peaks appear at the same location as the geometric

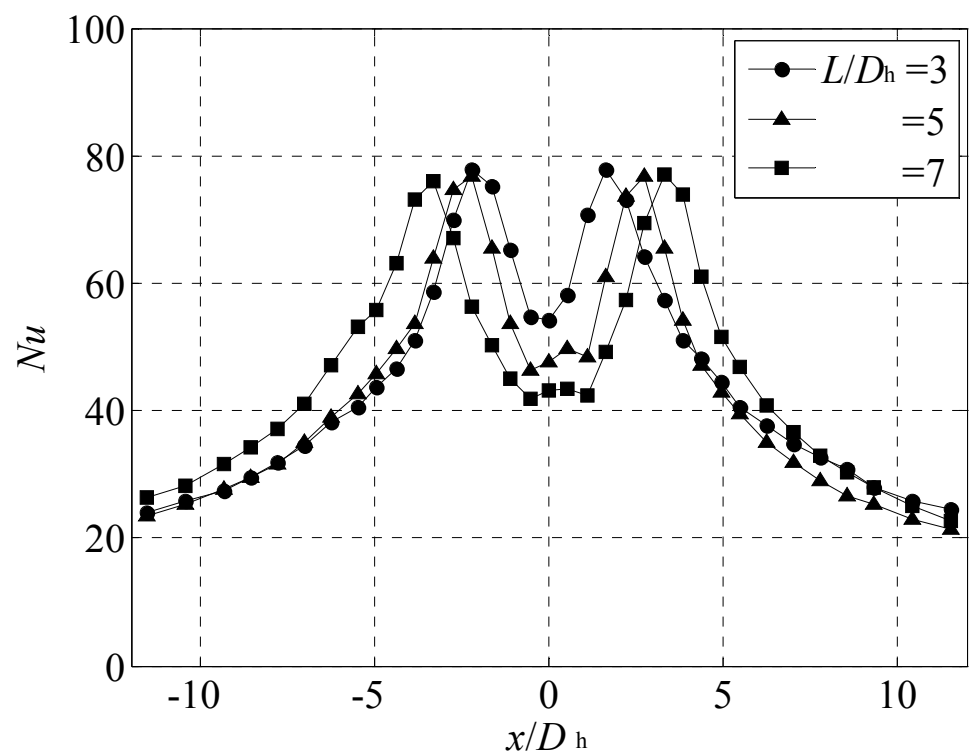

Figure 9: $\quad$ Local $\mathrm{Nu}$ for twin impinging jets $\left(\theta=0^{\circ}\right)$. 
stagnation point. The peak value appeared to be independent of the stagnation distance and increased about $2 \%$ higher than that of the single jet. The average $\mathrm{Nu}$ over the plate was enhanced by about $20 \%$ compared to the single jet; naturally, twin jets can improve the heat transfer on the target plate. A second peak appears at the center of the plate when the jet spacing is wide enough to produce rolling-up effects. However, a comparison of the second peaks at $L / \mathrm{D}_{\mathrm{h}}=5$ and 7 clearly indicates that the second peak at $L / \mathrm{D}_{\mathrm{h}}=5$ is higher than that at $L / D_{\mathrm{h}}=7$. This is attributed to the momentum loss decaying the impinging velocities of wall jets as the jet spacing increases. A higher second peak occurs when the jet spacing is smaller; however, when the jet spacing is too small, a second peak cannot be seen.

\subsection{Twin impinging jets inclined in the same direction}

Figure 10 demonstrates the local $\mathrm{Nu}$ at $L / \mathrm{D}_{\mathrm{h}}=3$ when the twin impinging jets are inclined in the same direction as shown in Figure 2 (b). The second peak, which appeared in the normal twin impinging jets, seems unclear in Figures 10 and 11, although the first two peaks appear in the vicinity of the impinging point in the same manner as in Figure 9. Both peaks in the uphill and the downhill side shifted towards the downstream on the plate. The peak on the uphill side gradually decreases as $\theta$ increases, while the peak on the downhill side rapidly decreases. In the case of $\theta=15$, the peak on the uphill side decreased about $10 \%$

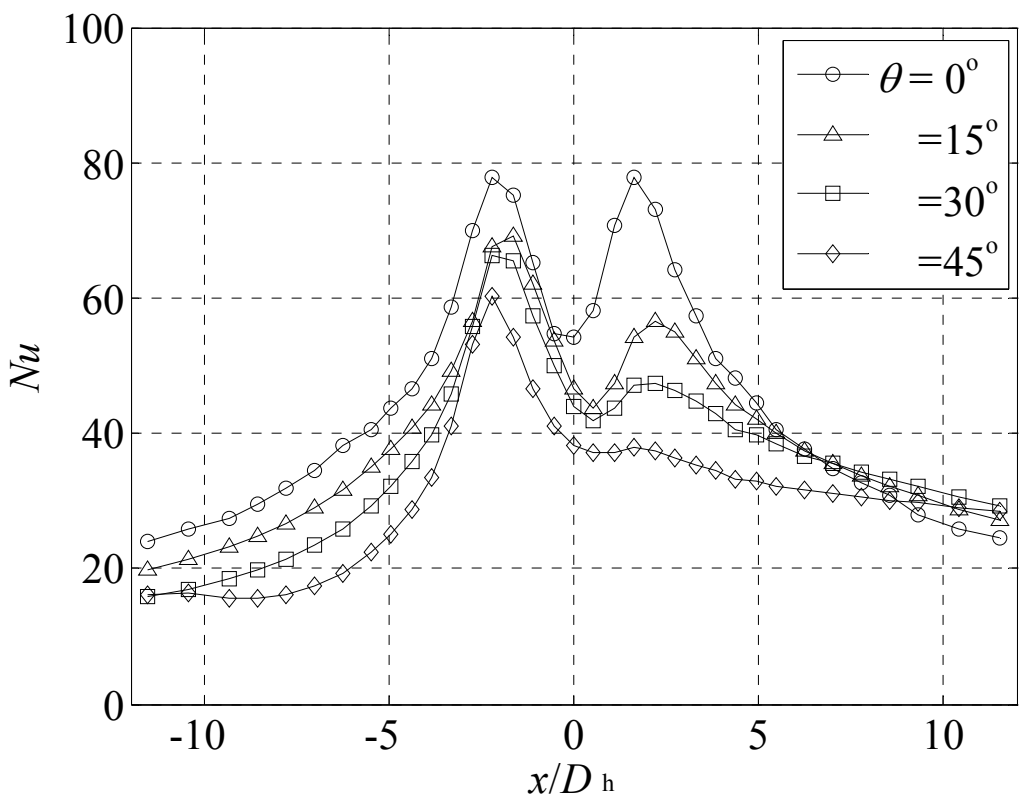

Figure 10: Local $\mathrm{Nu}$ for inclined twin impinging jets $\left(L / \mathrm{D}_{\mathrm{h}}=3\right)$ inclined in the same direction. 


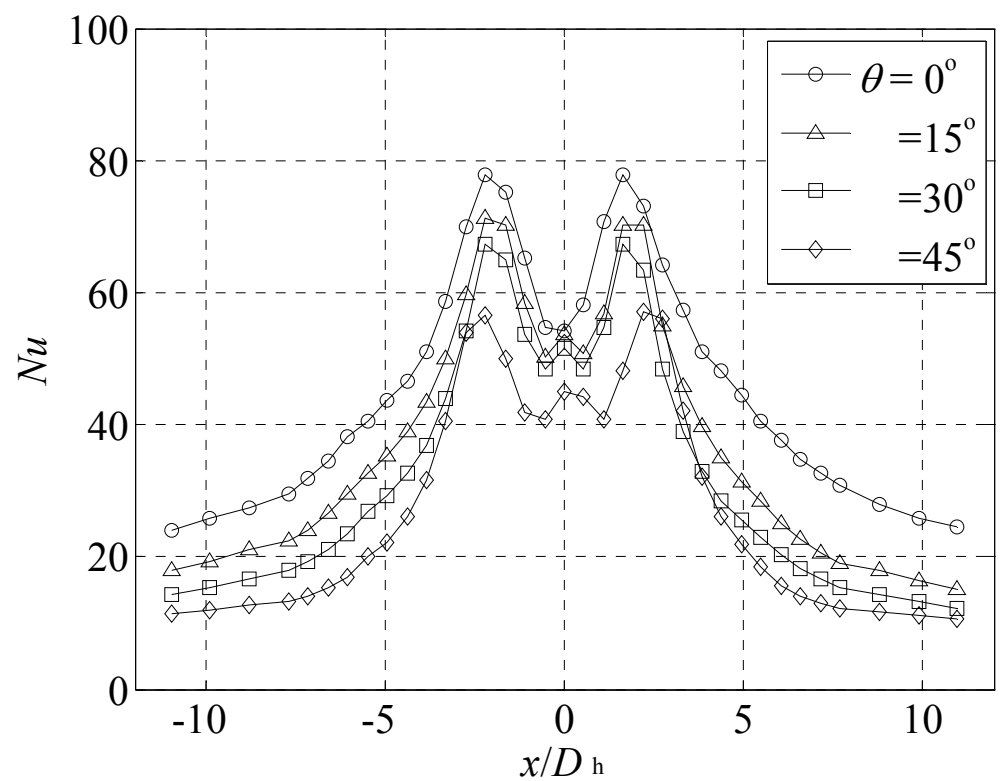

Figure 11: Local $\mathrm{Nu}$ for inclined twin impinging jets $\left(L / \mathrm{D}_{\mathrm{h}}=3\right)$ inclined to face each other.

compared with normal twin impinging jets at both $L / \mathrm{D}_{\mathrm{h}}=3$ and 5 and decreases about $15 \%$ at $L / \mathrm{D}_{\mathrm{h}}=7$. Therefore, the decrease of the average $\mathrm{Nu}$ did not extend beyond $5.4 \%$. On the other hand, the peaks on the downhill side decreased rapidly with increasing $\theta$ in contrast to those on the uphill side since the jet on the downhill side discourages the wall jet flow from the jet on the uphill side and its momentum decreases. For instance at $\theta=15^{\circ}$, the peak $\mathrm{Nu}$ in the downhill side decreased about $27 \%$ at $L / D_{\mathrm{h}}=3$, about $16 \%$ at $L / \mathrm{D}_{\mathrm{h}}=5$ and about $26 \%$ at $L / \mathrm{D}_{\mathrm{h}}$ $=7$.

Although the average $\mathrm{Nu}$ decreased as $\theta$ increased, a flat distribution of the local $\mathrm{Nu}$ on the downhill side was obtained. Therefore, uniform cooling on the downhill side was successfully achieved using an impinging jet. However, it is surprising that the average $\mathrm{Nu}$ of twin-jet impingement was lower than that of a single jet regardless of jet spacing except for at $\theta \leq 15^{\circ}$, suggesting that $\theta=15^{\circ}$ is the critical jet inclination to improve the heat transfer in the case of inclined cooling impingements. The average $\mathrm{Nu}$ at $\theta=15^{\circ}$ increases about $10 \%$ compared with that of a single jet.

\subsection{Twin impinging jets inclined to face each other}

Figure 11 shows the local $\mathrm{Nu}$ at $L / \mathrm{D}_{\mathrm{h}}=3$ when the twin impinging jets are inclined to face each other as shown in Figure 2 (c). In this case, the local $\mathrm{Nu}$ distribution is symmetrical in contrast to the case of the twin jets inclined in the same direction, and the heat transfer improved in the stagnation region 
$\left(-3<x / D_{h}<3\right)$ compared with the twin jets inclined in the same direction, although it fell significantly in the downstream.

The average $\mathrm{Nu}$ in the stagnation region compared with the twin jets inclined in the same direction is shown in Figure 12 and improved about $10 \%$ in the range of $\theta=15^{\circ}$ to $45^{\circ}$ at $L / \mathrm{D}_{\mathrm{h}}=3$. Each distribution in Figure 11 indicates the second $\mathrm{Nu}$ peak at the center of the jets $\left(x / \mathrm{D}_{\mathrm{h}}=0\right)$. The reason why the secondary peak $\mathrm{Nu}$ appeared is that the wall jet flowing from each nozzle impinges at the center, producing high turbulence intensity which contributes to breaking the thermal boundary layer along the plate. In the case of the impinging jet cooling, it is necessary to break the thermal boundary layer which is produced over the heated plate. The second $\mathrm{Nu}$ peak becomes smaller as the jet spacing increases because the wall jet flows lose kinetic energy at the time of impingement.

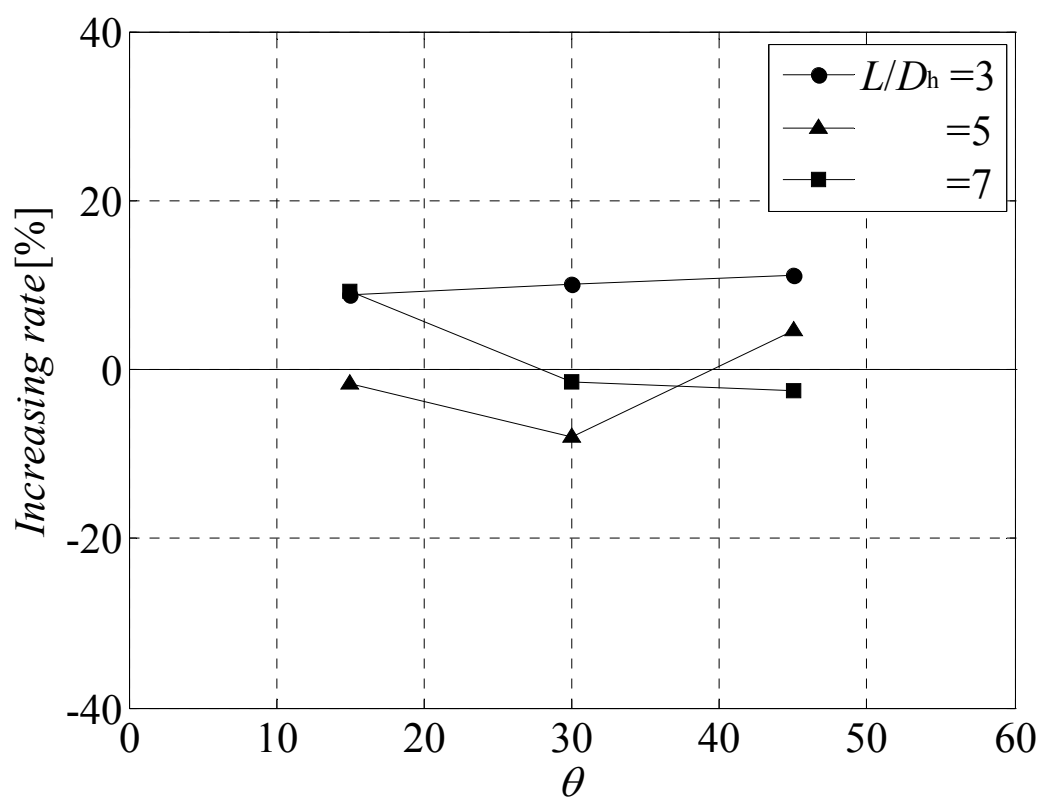

Figure 12: Increasing rate of the average $\mathrm{Nu}$ in the stagnation region compared with the twin jets inclined in the same direction.

\section{Conclusion}

The effects of inclination angle of impinging jets on cooling characteristics were investigated. We conducted three experiments: a single inclined impinging jet, twin impinging jets inclined in the same direction, and twin impinging jets inclined to face each other. The main results obtained were:

1) In the case of a single inclined jet, the local $\mathrm{Nu}$ increases in the downhill side as $\theta$ increases, while the $\mathrm{Nu}$ in the uphill side decreases. The average $\mathrm{Nu}(-12<\mathrm{x} / \mathrm{Dh}<12)$ improved up to $19 \%$ compared with that of $\theta=0^{\circ}$. The 
maximum $\mathrm{Nu}$ decreases as $\theta$ increases and the $\mathrm{Nu}$ peak position shifts towards the uphill side until $\theta=45^{\circ}$ and shifts back at $\theta \leq 45^{\circ}$.

2) In the case of normal twin jets, the first $\mathrm{Nu}$ peak appeared at the same position as the geometrical stagnation point. The first $\mathrm{Nu}$ peaks were little affected by jet spacing. The second $\mathrm{Nu}$ peak appeared at the center of the jet impingement points. The $\mathrm{Nu}$ peak was strongly affected by jet spacing. The average Nu improved about $20 \%$ compared with that of a single jet.

3) In the case of twin jets inclined in the same direction, the $\mathrm{Nu}$ peak increases on the downhill side and decreases on the uphill side with increasing $\theta$. The average $\mathrm{Nu}$ value gradually decreases on the downhill side and rapidly decreases on the uphill side with increasing $\theta$. Although the average $\mathrm{Nu}$ reduced with increasing $\theta$, a flat heat transfer distribution was successfully obtained.

4) In the case twin inclined jets facing each other, the average $\mathrm{Nu}$ in the stagnation region $\left(-3<x / \mathrm{D}_{\mathrm{h}}<3\right)$ improved about $10 \%$ compared with the twin jets inclined in the same direction.

\section{References}

[1] Lee, J. and Lee, S J., The effect of nozzle configuration on stagnation region heat transfer enhancement of axisymmetric jet impingement. Int. J. Heat and Mass Transfer, 43 (18), pp. 3497-3509, 2000.

[2] Kataoka, K., Suguro, M., Degawa, H., Maruo, K. and Mihata, I., Effect of Surface Renewal Due to Large-Scale Eddies on Jet Impingement Heat Transfer. Int. J. Heat and Mass Transfer, 30, pp. 559-567, 1987.

[3] Yokobori, S., Kasagi, N., Hirata, M. and Nishiwaki, N., Role of Large-Scale Eddy Structure on Enhancement of Heat Transfer in Stagnation Region of Two-Dimensional, Submerged, Impinging Jet. Proc. of the 6th Int. Heat Transfer Conf., Canada, pp. 305-310, 1978.

[4] R. Viskanta, Heat transfer to impinging isothermal gas and flame jets. Exp. Thermal and Fluid Science, 6, pp. 111-134, 1993.

[5] Beitelmal, A.H., Saad, MA. and Patel, C.D., The effect of inclination on the heat transfer between a flat surface and an impinging two-dimensional air jet. Int. J. Heat and Fluid Flow, 21, pp. 156-163, 2000.

[6] Abdel-Fattah, A., Numerical and experimental study of turbulent impinging twin-jet flow. Exp. Thermal and Fluid Sci., 31, pp. 1061-1072, 2007.

[7] JSME Data Book; Heat Transfer $5^{\text {th }}$ Edition, pp. 39-51, 2009. 